\title{
FORMAÇÃO DE PROFESSORES NA EXTENSÃ̃ UNIVERSITÁRIA: Uma análise das perspectivas e limites
}

\author{
Andréa Kochhann ${ }^{(*)}$
}

\section{INTRODUÇÃO}

A formação de professores, tanto inicial quanto continuada, tem sido objeto de vários estudos. Esse texto é fruto de uma pesquisa de doutorado em educação delimitado em um dos componentes curriculares de formação de professores, no Brasil, que é a extensão universitária. A extensão universitária é discutida por Reis (1989) em duas linhas de concepção, uma eventistainorgânica como prestação de serviços ou atividades esporádicas desvinculadas do contexto e do processo de aprendizagem e outra processual-orgânica, permanente e imersa no processo formativo e produção de conhecimento, em parceria com a sociedade de forma oxigenante e transformadora. O autor ainda apresenta que a extensão universitária ao compor os currículos, precisa ser compreendida pela Instituição como vertente formadora de professores e não somente que atende as demandas sociais, principalmente pelo assistencialismo.

O objetivo deste estudo é analisar os limites e as perspectivas quanto à formação de professores no espaço da extensão universitária como componente curricular da universidade, utilizando o estado do conhecimento, revisitando a produção de teses e dissertações e os periódicos da área de educação A1, na Coordenação de Aperfeiçoamento de Pessoal de Nível Superior (Capes) e no GT 08 - Formação de Professores da Associação Nacional de Pós-Graduação e Pesquisa em Educação (Anped), pelo descritor "Extensão Universitária”. A delimitação nos periódicos e na Capes, foi entre 2013 e 2016, devido disponibilidade dos dados e a Anped em sua extensão. A busca foi pelo título, palavras-chave e resumo. A análise dos trabalhos encontrados foi no texto completo.

A compreensão sobre as concepções de extensão universitária é importante pois, a mesma pode ser uma constituinte na formação de professores, enquanto ambiência acadêmica, ao promover a unidade teoria e prática, fomentar a produção do conhecimento científico, possibilitar a efetivação do tripé universitário, favorecer uma formação política e emancipadora se, a

\footnotetext{
${ }^{(*)}$ Docente da Universidade Estadual de Goiás (UEG). Pedagoga pela Universidade Estadual de Goiás (UEG). Especialista em Docência Universitária pela Universidade Estadual de Goiás (UEG). Mestre em Educação pela Pontifícia Universidade Católica de Goiás (PUC-GO). Doutoranda em Educação pela Universidade da Universidade de Brasília (UnB). E-mail: andreakochhann@yahoo.com.br.
} 
temporalidade das ações de extensão forem permanentes, devido a assumência das instâncias competentes. Essas categorias do objeto emergiram das análises nos trabalhos encontrados pelo estado do conhecimento, apresentando contradição e dialética.

\section{FORMAÇÃO DE PROFESSORES PELA EXTENSÃO UNIVERSITÁRIA: O QUE REVELAM OS TRABALHOS?}

Para discutir a formação de professores na extensão universitária foi realizada uma busca em periódicos A1, dissertações e teses na Capes e no GT 08 - Formação de Professores da Anped. Pela busca totalizam 46 periódicos classificadas como A1. Destes 46, foram analisados as na língua portuguesa, que disponibilizam as informações online e que discutem sobre formação de professores. Assim, foram delimitados cinco periódicos, sendo Cadernos CEDES, Cadernos de Pesquisa, Educação e Realidade, Educação e Sociedade e Pró-Posições.

Os Cadernos CEDES - Centro de Estudos em Educação e Sociedade publicaram 4 volumes, com 12 números, totalizando 99 trabalhos, distribuídos em várias temáticas da educação. Foi encontrado 1 trabalho. Os Cadernos de Pesquisa publicaram 4 volumes, com 14 números, totalizando 211 trabalhos, distribuídos em várias temáticas da educação. Não foi encontrado nenhum trabalho. A Revista Educação e Realidade publicou 4 volumes, com 17 números, totalizando 284 trabalhos, distribuídos em várias temáticas da educação. Não foi encontrado encontrou nenhum trabalho. A Revista Educação e Sociedade publicou 4 volumes, com 15 números, totalizando 241 trabalhos, distribuídos em várias temáticas da educação. Não foi encontrado encontrou nenhum trabalho. A Revista Pró-Posições publicou quatro volumes, com doze números, totalizando 179 trabalhos, distribuídos em várias temáticas da educação. Não foi encontrado nenhum trabalho. Pelo mapeamento e análise das Revistas Qualis A1 organizou-se a aproximação entre formação e extensão universitária, conforme disposto no Quadro. 01.

QUADRO 01. TOTAL DE TRABALHOS DE REVISTAS A1

\begin{tabular}{|l|l|l|}
\hline REVISTA A1 & Trabalhos & Aproximação entre formação e extensão \\
\hline Cadernos Cedes & 99 & 1 \\
\hline Cadernos de Pesquisa & 211 & - \\
\hline Educação e Realidade & 284 & - \\
\hline Educação e Sociedade & 241 & - \\
\hline Pró-Posições & 179 & - \\
\hline TOTAL & 1014 & 1 \\
\hline
\end{tabular}

Fonte: Produto da pesquisa. 
No banco de teses e dissertação da Capes, foram encontrados 58 trabalhos, com o descritor "Extensão Universitária", tendo como área de concentração as áreas afins com o objeto de estudo deste trabalho, conforme Quadro 02.

\section{QUADRO 02. TESES E DISSERTAÇÕES DA CAPES.}

\begin{tabular}{|l|l|l|l|}
\hline Área de concentração & Dissertações & Teses & Total \\
\hline Educação & 33 & 10 & 43 \\
\hline Educação, Sociedade e Práxis Pedagógica & - & 1 & 1 \\
\hline Ensino e Aprendizagem & 8 & - & 8 \\
\hline Educação Escolar & 2 & 1 & 3 \\
\hline Formação de Professores & 1 & - & 1 \\
\hline TOTAL & 44 & 12 & 56 \\
\hline
\end{tabular}

Fonte: Produto da pesquisa

Dos 56 trabalhos encontrados nas áreas de concentração Educação; Educação, Sociedade e Práxis Pedagógica; Ensino e Aprendizagem; Educação Escolar e Formação de Professores, totalizou oito trabalhos que apresentaram discussão da formação de professores na extensão universitária, conforme Quadro 03.

\section{QUADRO 03. TRABALHOS DA CAPES}

\begin{tabular}{|l|l|l|}
\hline Área & Total & $\begin{array}{l}\text { Aproximação entre formação e } \\
\text { extensão }\end{array}$ \\
\hline Educação & 43 & 4 \\
\hline Educação, Sociedade e Práxis Pedagógica & 1 & 1 \\
\hline Ensino e Aprendizagem & 8 & 1 \\
\hline Educação Escolar & 3 & 1 \\
\hline Formação de Professores & 1 & 1 \\
\hline Total & 56 & 8 \\
\hline
\end{tabular}

Fonte: Produto da pesquisa

A Anped, de 1978 até 2017, realizou 38 reuniões, organizada por GTs - Grupos de Trabalhos. Um deles é o GT 08 - Formação de Professores, constante da Anped a partir da 23a . A análise dos trabalhos foi até a $36^{\mathrm{a}}$ reunião, pois a $37^{\mathrm{a}}$ não haviam disponibilizado os anais. Da $23^{\mathrm{a}}$ à $36^{\mathrm{a}}$ reunião, foram encontrados dois trabalhos que trataram a formação de professores na extensão universitária, conforme o Quadro 04. 
QUADRO 4. TRABALHOS DO GT 08 DA ANPED,

\begin{tabular}{|l|l|l|l|l|l|l|l|l|l|l|l|l|l|l|l|l|}
\hline Reunião & $23^{\mathrm{a}}$ & $24^{\mathrm{a}}$ & $25^{\mathrm{a}}$ & $26^{\mathrm{a}}$ & $27^{\mathrm{a}}$ & $28^{\mathrm{a}}$ & $29^{\mathrm{a}}$ & $30^{\mathrm{a}}$ & $31^{\mathrm{a}}$ & $32^{\mathrm{a}}$ & $33^{\mathrm{a}}$ & $34^{\mathrm{a}}$ & $35^{\mathrm{a}}$ & $36^{\mathrm{a}}$ & $37^{\mathrm{a}}$ & TOTAL \\
\hline Trabalhos & 11 & 17 & 10 & 12 & 22 & 45 & 29 & 31 & 18 & 21 & 21 & 22 & 22 & 18 & - & 299 \\
\hline $\begin{array}{l}\text { Aproximação } \\
\text { entre } \\
\text { formação } \\
\text { extensão }\end{array}$ & $\mathbf{e}$ & & & & 1 & & & & & 1 & & & & & & 2 \\
\hline
\end{tabular}

Fonte: Produto da pesquisa

Dos 1014 trabalhos encontrados nas revistas A1, um abordou a temática formação de professores na extensão universitária. Dos 56 encontrados na Capes, oito abordaram. Dos 299 encontrados no GT 08 da Anped, dois abordaram. Os trabalhos totalizam 1369 e destes, onze se tornaram objeto de análise, conforme Quadro 05.

QUADRO 05, TOTAL GERAL DOS TRABALHOS.

\begin{tabular}{|l|l|l|}
\hline \multicolumn{1}{|c|}{ Objeto } & \multicolumn{1}{c|}{ Geral } & \multicolumn{1}{c|}{ Aproximações } \\
\hline Revistas A1 & 1014 & 8 \\
\hline Capes & 56 & 2 \\
\hline Anped & 299 & 11 \\
\hline TOTAL & 1369 & 1 \\
\hline
\end{tabular}

Fonte: Produto da pesquisa.

Os onze trabalhos que apresentam a aproximação na discussão sobre a formação de professores na extensão universitária estão dispostos no Quadro 06.

QUADRO 06. APRESENTAÇÃO DOS TRABALHOS.

\begin{tabular}{|l|l|l|l|}
\hline Objeto & Título & Autores & Palavras-chave \\
\hline A1 & $\begin{array}{l}\text { Travessias na EJA: a extensão } \\
\text { universitária como ponte do } \\
\text { fazer, do aprender, do pensar }\end{array}$ & $\begin{array}{l}\text { CAMARGO, Maria } \\
\text { Rosa R, Martins; } \\
\text { MIGUEL, José Carlos; } \\
\text { ZANATA, Eliana } \\
\text { Marques }\end{array}$ & $\begin{array}{l}\text { Educação de jovens e } \\
\text { adultos; extensão } \\
\text { universitária; saberes } \\
\text { compartilhados; saberes } \\
\text { produzidos }\end{array}$ \\
\hline Capes - Educação & $\begin{array}{l}\text { Extensão universitária e } \\
\text { formação política na } \\
\text { universidade pública: o caso } \\
\text { Projeto Rondon na UFRGS e na } \\
\text { UDESC }\end{array}$ & $\begin{array}{l}\text { CASTRO, Aline } \\
\text { Tamires Kroetz Ayres }\end{array}$ & $\begin{array}{l}\text { Formação política. } \\
\text { universidade pública. } \\
\text { extensão universitária. } \\
\text { Projeto Rondon }\end{array}$ \\
\hline Capes - Educação & $\begin{array}{l}\text { Universidade e escola básica: o } \\
\text { papel da extensão universitária } \\
\text { na formação de professoras e } \\
\text { professores em educação } \\
\text { científica }\end{array}$ & $\begin{array}{l}\text { ABREU, Sandra } \\
\text { Cristina Souza Reis }\end{array}$ & $\begin{array}{l}\text { Educação científica, } \\
\text { teoria crítica, extensão } \\
\text { universitária, mão na } \\
\text { massa, ensino } \\
\text { fundamental, química } \\
\text { verde }\end{array}$ \\
\hline Capes - Educação & $\begin{array}{l}\text { A experiência como prática } \\
\text { formativa de estudantes na }\end{array}$ & $\begin{array}{l}\text { CUNHA, Ana Luiza } \\
\text { Salgado }\end{array}$ & $\begin{array}{l}\text { Experiência; extensão } \\
\text { universitária; formação }\end{array}$ \\
\hline
\end{tabular}




\begin{tabular}{|c|c|c|c|}
\hline & extensão & & discente. \\
\hline Capes - Educação & $\begin{array}{l}\text { Formação política na } \\
\text { universidade: possibilidades a } \\
\text { partir de (con)vivências na } \\
\text { extensão/UFRGS }\end{array}$ & ZIRGER, Juliana & $\begin{array}{l}\text { Política educacional, } \\
\text { universidade, extensão }\end{array}$ \\
\hline $\begin{array}{l}\text { Capes - Educação, } \\
\text { Sociedade e Práxis } \\
\text { Pedagógica }\end{array}$ & $\begin{array}{l}\text { A extensão universitária e os } \\
\text { entrelaços de saberes }\end{array}$ & $\begin{array}{l}\text { JUNIOR, Alcides Leão } \\
\text { Santos }\end{array}$ & $\begin{array}{l}\text { extensão universitária. } \\
\text { comunidade e } \\
\text { universidade. }\end{array}$ \\
\hline $\begin{array}{l}\text { Capes }- \text { Ensino e } \\
\text { Aprendizagem }\end{array}$ & $\begin{array}{l}\text { As contribuições da extensão } \\
\text { universitária para o processo de } \\
\text { aprendizagem, prática da } \\
\text { cidadania e exercício profissional }\end{array}$ & $\begin{array}{l}\text { DUARTE, Jacildo da } \\
\text { Silva }\end{array}$ & $\begin{array}{l}\text { Aprendizagem, atuação } \\
\text { profissional, cidadania, } \\
\text { extensão universitária, } \\
\text { projeto de extensão }\end{array}$ \\
\hline $\begin{array}{l}\text { Capes - Educação } \\
\text { Escolar }\end{array}$ & $\begin{array}{l}\text { A formação de professores para o } \\
\text { trabalho com deficientes visuais: } \\
\text { Uma experiência inicial de } \\
\text { colaboração a partir do } \\
\text { desenvolvimento de materiais } \\
\text { didáticos. }\end{array}$ & $\begin{array}{l}\text { OTALARA, Aline } \\
\text { Piccoli }\end{array}$ & $\begin{array}{l}\text { Educação especial. } \\
\text { formação de } \\
\text { professores. deficiência } \\
\text { visual. } \\
\text { Colaboração. Material } \\
\text { didático. }\end{array}$ \\
\hline $\begin{array}{l}\text { Capes - Formação } \\
\text { de Professores }\end{array}$ & $\begin{array}{l}\text { Educação não escolar e saberes } \\
\text { docentes na formação do } \\
\text { pedagogo: análise de uma } \\
\text { experiência no espaço hospitalar }\end{array}$ & RABELO, Francy Sousa & $\begin{array}{l}\text { Educação não escolar. } \\
\text { formação inicial do } \\
\text { pedagogo. saberes } \\
\text { docentes. atendimento } \\
\text { escolar hospitalar. }\end{array}$ \\
\hline $\begin{array}{ll}\text { Anped - GT } & 08 \text { - } \\
\text { Formação } & \text { de } \\
\text { Professores } & \end{array}$ & $\begin{array}{l}\text { A universidade e a formação } \\
\text { continuada de professores: } \\
\text { Dialogando sobre a autonomia } \\
\text { profissional. }\end{array}$ & $\begin{array}{l}\text { SANTOS, Sonia Regina } \\
\text { Mendes dos }\end{array}$ & $\begin{array}{l}\text { Autonomia profissional, } \\
\text { formação continuada de } \\
\text { professores, } \\
\text { universidade }\end{array}$ \\
\hline $\begin{array}{ll}\text { Anped - GT } & 08 \text { - } \\
\text { Formação } & \text { de } \\
\text { Professores } & \end{array}$ & $\begin{array}{l}\text { Formação dos profissionais da } \\
\text { educação: a revista brasileira de } \\
\text { política e administração da } \\
\text { educação (RBPAE) e o } \\
\text { compromisso da universidade }\end{array}$ & $\begin{array}{l}\text { MAIA, Graziela } \\
\text { Zambão Abdian }\end{array}$ & $\begin{array}{l}\text { Formação dos } \\
\text { profissionais da } \\
\text { educação; publicações } \\
\text { da Anpae; compromisso } \\
\text { social da universidade. }\end{array}$ \\
\hline
\end{tabular}

Fonte: Produto da pesquisa

Dos 1369 trabalhos encontrados, totalizam onze trabalhos que possibilitam uma análise sobre a formação de professores no espaço da extensão universitária como componente curricular da universidade. Para compreender como esse processo ocorre é importante desvelar as perspectivas e os limites.

\section{FORMAÇÃO DE PROFESSORES NA EXTENSÃO UNIVERSITÁRIA: QUAIS AS PERSPECTIVAS E OS LIMITES NOS TRABALHOS?}

Os onze trabalhos encontrados foram analisados em sua íntegra e organizada uma síntese com base no objeto, no problema, partícipes e nas principais considerações, visando compreender como a formação de professores na extensão universitária foi construída e desvelar os limites e as perspectivas. 
O trabalho de Camargo, Miguel e Zanata (2015) analisou o Programa de Educação de Jovens e Adultos (Peja), desenvolvido como extensão, desde 2001, pela Universidade Estadual Paulista "Júlio de Mesquita Filho" (Unesp), promovendo a produção de conhecimento e formação de educadores, com licenciandos que acompanham pessoas de pouca ou sem nenhum escolarização, pela teoria histórico-cultural. Defendem que a EJA tem especificidade e que é importante formação do PEJA, pela metodologia investigativa sobre as dificuldades e necessidades dos educandos, bem como da articulação entre prática e teoria, possibilitando aprendizagem significativa. O problema foi "articular algumas reflexões acerca da produção de conhecimento sobre Educação de Jovens e Adultos (EJA) na dinâmica da extensão universitária, tomando como exemplo o Programa de Educação de Jovens e Adultos (Peja/Unesp)" se preocupando com os objetivos que o mesmo apresentou e suas realizações, bem como vivências, saberes e dizeres dos seus atores - docentes em formação. Os partícipes do PEJA foram a comunidade externa e os servidores da instituição com baixa ou nenhuma escolaridade, valendo-se de docentes de Pedagogia e Letras, bolsistas, voluntários e estagiários. Evidenciou-se que é preciso uma relação dialógica para trabalhar no PEJA, estabelecer vínculos com a sociedade, repensar as atividades pedagógicas mediante a realidade, possibilitar o conhecimento interdisciplinar, entender a EJA como questão política e não só técnica, visando uma formação humana. O PEJA possibilita "uma educação que se pauta no fazer, aprender e pensar, como impulsionadoras de metodologias e tecnologias outras, que daí podem advir". Para os autores o PEJA, é "uma das ações da universidade voltada à articulação entre teoria e prática nessa área do conhecimento e à integração da universidade à comunidade. Está em pauta contribuir para minimizar o analfabetismo, produzir material didático e bibliográfico e pôr em discussão políticas públicas [...]". Defendem que nas "Ciências Humanas a pesquisa tem campo fértil na extensão universitária", e que "O processo de formação de educadores para a EJA, pela via de um projeto de extensão universitária, constitui-se como um espaço no qual uma ação de cunho social se torna objeto de interesse para a pesquisa e para o ensino".

O trabalho de Castro (2015) analisou o Projeto Rondon, como projeto de extensão, refletindo sobre sua importância no contexto neoliberal e suas contribuições para a formação política dos estudantes. O autor questionou modelos e práticas formativas na universidade que tendem a mera profissionalização e aquisição de habilidades técnicas, sendo que deveriam possibilitar a transformação social por teorias contra-hegemônicas. O problema foi "Quais são as contribuições das atividades extensionistas do Projeto Rondon enquanto espaço potencial de formação política dos estudantes na universidade pública?”. Os partícipes da pesquisa foram os estudantes e docentes rondonistas da Universidade Federal do Rio Grande do Sul e da Universidade 
do Estado de Santa Catarina, dos cursos de Geografia, Direito, Jornalismo, Engenharia Civil, Arquitetura e Urbanismo, Ciências Biológicas, Educação Física, Engenharia Elétrica e História. O autor apresentou possíveis contribuições do Projeto Rondon, possibilitando uma formação política aos estudantes que participam do mesmo, pois são "comprometidos com os processos de emancipação e valorização da dignidade humana". Apresentou também como contribuições "a ampliação da formação acadêmica para além dos aspectos técnicos e profissionais, na medida em que se identifica o potencial interdisciplinar e dialógico da experiência e a possibilidade de relacionar teoria e prática a partir de uma práxis comprometida com a transformação social” e como fragilidades do Projeto Rondon apresentou "a descontinuidade das ações, a inexistência de um processo de avaliação participativa e o distanciamento entre a coordenação feita pelo Ministério da Defesa e as instituições de ensino, o que compromete o efetivo engajamento destas com o Projeto Rondon enquanto espaço de formação e comprometimento social" e afirmou que "considera-se que a experiência extensionista do Projeto Rondon apresenta potencialidades e fragilidades para a constituição de sujeitos políticos, críticos, reflexivos e socialmente comprometidos com os processos de emancipação e valorização da dignidade humana”.

O trabalho de Abreu (2015) analisou o desenvolvimento de um projeto de extensão, com acadêmicos de licenciatura em Pedagogia e Química, verificando nuances da formação inicial docente e o processo da educação científica, com foco nas questões verdes e socioambientais, pela metodologia da Química Verde. O problema não foi exposto como pergunta, mas encontramos que o espaço educacional decorrente da extensão, também possibilita e, em certa medida, abarcar os âmbitos sociais, científicos e educacionais do contexto da universidade (licenciatura) e escolas de ensino fundamental, anos iniciais; b) é possível a formação inicial de estudantes das licenciaturas em Pedagogia e Química ao se vincularem à extensão, ampliar espaços e ações de formação de professoras e professores com reflexo favorável na atuação docente em Ciências da Natureza e suas Tecnologias (CNTec), vinculadas às escolas de um sistema formativo. Os partícipes foram grupos de professoras e professores e estudantes de licenciatura de Pedagogia e Química da universidade do litoral sul da Bahia e escolas de ensino fundamental pelo Projeto de Extensão Programa Mão na Massa (MnM), em 2014. O autor observou "a necessidade de um pensar-agir sobre a formação inicial e atuação docente na educação científica", e potencial para a práxis da tendência emancipatória com “a revisão dos modos de articulação entre a universidade e as escolas de educação básica quanto à posição e às formas de agir e pensar o lócus da escola pública, universidade, extensão e políticas de acesso do indivíduo e de coletivos locais aos conhecimentos da educação e ciências, pode promover a experiência formativa a todos os envolvidos". Para o autor 
é preciso "rever a articulação escola - universidade quanto à posição e ao modo de agir e pensar o lócus da escola pública, da extensão e da política de acesso do indivíduo e de coletivos locais aos recursos e conhecimentos das CNTec" e por isso deve-se "constituir outra episteme, empreendida como tendência interpretativa emancipatória".

O trabalho de Cunha (2013) analisou a prática formativa de graduandos a partir de experiências extensionistas, entendendo como percebem a extensão em sua formação acadêmica, apontando os significados e sentidos das experiências na construção do conhecimento acadêmico. O problema foi "quais são os impactos causados na formação do estudante universitário que está inserido em atividades de extensão? Qual o modo como os estudantes tratam suas experiências em Extensão na sua formação acadêmica? Como foram construídas, historicamente, as diferentes concepções e modalidades de Extensão Universitária, associadas às diferentes funções assumidas pela universidade? E ainda, quais as diferenças sociais e políticas nas concepções e modalidades de Extensão Universitária e como estas impactam na construção das diferentes experiências formativas de estudantes?" Os partícipes das áreas de agrárias, biológicas, ciências exatas e humanas, tendo alunos de pedagogia, da Universidade Federal de Viçosa, de projetos de extensão, de 2011. O autor concluiu que não ocorre um conhecimento dialógico e coletivo, mas "a existência de outras formas de tecer conhecimentos, nos quais a Extensão Universitária aparece como uma das possibilidades de espaços para outros tantos conhecimentos que se anunciam como novos paradigmas", bem como que os estudantes entendem a "Extensão Universitária enquanto possível espaço privilegiado para consolidação de outros conhecimentos, através da abertura da universidade a outros sujeitos e os saberes por eles tecidos." e que "saberes fundamentados no vivido, bem como saberes constituídos por experiências tornam-se práticas formativas de igual valor aos saberes já legitimados. Temos, então, claramente, que as experiências em Extensão Universitária consistem em possíveis pontos de reconfiguração da universidade que busca direcionar-se à emancipação".

O trabalho de Zirger (2013) analisou as contribuições das ações extensionistas para uma formação mais humana e política no espaço acadêmico. O problema foi "Como as experiências percebidas pelos estudantes, no contexto das ações de extensão direcionadas pelo Plano Nacional de Extensão Universitária (PNE), no Programa Convivências, contribuem na formação do sujeito político na universidade? Quais os conceitos presentes no PNE sobre extensão, responsabilidade social da universidade e formação política se evidenciam nas percepções dos estudantes?’. Os partícipes que são estudantes dos cursos de Medicina, Farmácia, Enfermagem, Psicologia, Nutrição, Biociência, bem como professores e técnicos administrativos. O autor conclui que há "indícios que permitem pensar uma aproximação da extensão com a formação política na universidade, bem 
como a qualificação da formação acadêmica a partir das relações entre teoria e prática e do contato com realidades diversas", mesmo com tensões, para o autor é possível que as ações de extensão sejam "uma experiência potencializadora da formação na universidade a partir do reconhecimento dos saberes plurais." e finaliza que "Os resultados elucidam tensionamentos em relação às concepções de extensão e sobre as suas contribuições sociais. Mas os dados também trazem indícios que permitem pensar uma aproximação da extensão com a formação política na universidade, bem como a qualificação da formação acadêmica a partir das relações entre teoria e prática e do contato com realidades diversas".

O trabalho de Junior (2013) analisou ações extensionistas, na visão dos egressos, enquanto produtoras de conhecimento devido às experiências dos partícipes enquanto autores e coautores de autonomia e interdependência, pela relação dialógica. O problema foi "Uma ação de extensão universitária de cunho acadêmico favorece o entrelaçamento de saberes?”. Os partícipes, foram egressos dos cursos de Farmácia, Direito, Educação Física, Fonoaudiologia, Dança, Museologia, Arquitetura, Jornalismo, Veterinária e Engenharia, da UFBA e que no seu processo (in) formativo participaram de uma Atividade Curricular em Comunidade como projeto de extensão, do Campus de Caicó, em 2007. O autor concluiu que “[...] os extensionistas ganham uma dimensão de dialogicidade, de inter-relacionamento e uma sólida contextualização da realidade tendo em vista que nela o diálogo entre os conhecimentos acadêmicos e culturais possibilita a democratização do conhecimento", bem como "Em suma, uma ACC é um processo formativo onde a teoria e a prática perdem as fronteiras da disciplinaridade sem tornarem-se excludentes. Dessa forma, nossa aposta para que esta ação aconteça de fato reside na extensão de cunho acadêmico que, diferente das práticas de extensão de cunho mercantilista e assistencialista, ela visa, o diálogo", defendendo que a "Pedagogia dos entre-laços de saber vislumbra que, nas ações de extensão universitária, está impressa uma consistência teórica e operacional de que sua efetividade necessita”.

O trabalho de Duarte (2014) discutiu sobre as contribuições dos projetos de extensão para a aprendizagem, prática da cidadania e atuação profissional. O problema foi "Como os projetos de Extensão Universitária contribuem para facilitar o processo de aprendizagem? Que fatores envolvidos na execução dos projetos de extensão contribuíram para a atuação dos alunos como cidadãos junto à comunidade? Que fatores intervieram positivamente e contribuíram para incrementar o desempenho da atuação profissional desses universitários?”. Os partícipes foram mais de cem estudantes de graduação de Agronomia, Direito, Administração de Empresas, Psicologia de 15 instituições. O autor concluiu que a participação em projetos de extensão é relevante no processo de aprendizagem, bem como traz contribuições significativas na atuação dos 
estudantes e na sua formação para a cidadania e atuação profissional, pois "potencializa e estimula a aprendizagem, tornando-a mais humana na medida em que estreita os laços da universidade com a realidade econômica, social, política e cultural, quebrando a visão dualista da razão instrumental[...]”. O autor apresentou contribuições da extensão no processo de aprendizagem, pois "colocaram em prática a teoria, tiveram contato com a realidade social, puderam discutir questões práticas para interferir na realidade da comunidade, foram capazes de se exporem, serem questionados e questionarem, expressaram suas opiniões, sugeriram mudanças decorrentes das experiências nos projetos de extensão e não se omitiram diante da necessidade percebida durante a execução dos projetos". Como potencialidades o autor defendeu que "Extensão Universitária emancipadora não se caracteriza como teoria, mas como ponto central da práxis articuladora da teoria e prática, que permite desvendar os determinantes da realidade social em sua totalidade”.

O trabalho de Otalara (2014) avaliou a formação inicial e continuada de professores em um curso de extensão sobre o desenvolvimento de materiais didáticos para pessoas com deficiência visual. O problema foi "Como ocorre a formação inicial e continuada de professores para trabalhar com pessoas com deficiência visual?”. Os partícipes foram uma professora de uma instituição para cegos, uma professora de sala de recurso da rede estadual de ensino, uma professora universitária de instituição pública federal, uma aluna de licenciatura e duas alunas cursando Pedagogia. O autor avaliou o processo formativo dos futuros profissionais para trabalhar com deficientes visuais e identificou certo distanciamento entre a teoria e a prática na formação de professores inicial e continuada, concluindo que a formação é insuficiente "embora tenham evidenciado que tanto para a formação inicial quanto continuada, há a necessidade de que se tenha uma preocupação com a atuação prática do professor. Para os cursos de formação inicial percebeu-se que a interdisciplinaridade parece ser uma alternativa mais viável do que a inserção de disciplinas específicas, visando essa escola inclusiva.

O trabalho de Rabelo (2014) tratou da formação inicial do pedagogo para o atendimento escolar hospitalar com base em um projeto de extensão, analisando as tensões, limitações e possibilidades na realização de experiências educacionais não escolares no hospital, chegando a três categorias de análise: a educação não escolar no hospital, formação inicial do pedagogo e saberes docentes. O problema foi "quais os saberes constituídos na formação inicial do pedagogo, quando vinculada à educação não escolar desenvolvida em hospital, neste caso em um projeto de extensão universitária?". Os partícipes egressos do Curso de Pedagogia da UFMA, que participaram do projeto de extensão, entre 2008 e 2012, que apresentaram monografia ou trabalho científico acerca de temática que envolveu o projeto e estarem atuando em sala de aula regular. A experiência 
extensionista promoveu a defesa de monografias e trabalhos em eventos científicos, possibilitando a relação entre pesquisa, ensino e extensão. Foi evidenciado que o currículo não viabiliza a práxis, apontando "limitações na formação inicial do pedagogo especificamente aos campos de atuação do pedagogo além da escola", mas, afirmam que a vivência "tornou-as mais humanizadas, mais comprometidas com seu fazer docente". Para o autor

"Os resultados confirmaram que a formação inicial do pedagogo ancorada na educação não escolar pela extensão universitária contribui na produção de saberes voltados à humanização e à sensibilidade, além de todos os saberes da formação profissional necessários ao futuro pedagogo para o exercício docente, bem como demonstra que os saberes e práticas experienciados no hospital promovem um perfil docente humanizado com atenção profícua à criança hospitalizada."

O trabalho de Santos (2004) discute a formação de professores nas últimas décadas apontando que tem se dirigido para o professor reflexivo e autonomia e, que as universidades têm a função de promover a formação de professores continuada, por meio das Pró-Reitorias de Extensão. O problema foi "Quais são as principais atividades desenvolvidas pelas universidades para a formação continuada de professores?", que resultou na publicação do referido artigo, em que "O estudo realizado em todas as universidades públicas do estado do Rio de Janeiro e em uma particular buscou investigar a existência de propostas voltadas para a formação de professores e a contribuição que trazem para a autonomia profissional”. Os partícipes foram profissionais que coordenavam programas e projetos na Universidade do Estado do Rio de Janeiro (UERJ); Universidade Estadual do Norte Fluminense (UENF); Universidade Federal Fluminense (UFF); Universidade Federal do Rio de Janeiro (UFRJ); Universidade do Rio de Janeiro (UNIRIO) e da Pontifícia Universidade Católica do Rio de Janeiro (PUC-RJ). A pesquisa constatou que a continuada ficava mesmo a cargo das instituições públicas e com cursos de no máximo 80 horas e que somente uma instituição particular oferecia um curso de Pós-Graduação Latu Senso. Pela análise conclui-se que "são poucas as garantias de que os professores que são alvo dos programas de formação contínua terão ampliadas suas capacidades de manejar conhecimento". Os recursos para a realização dos cursos de extensão vêm da parceria com as secretarias municipais de educação, enquanto outras não recebem ajuda nenhuma. Em alguns casos os parceiros ofertam transporte e alimentação. A autora apresenta que uma dificuldade é "a falta de uma política interna que possa ter reflexos na sistematização das atividades destinadas à formação de professores no âmbito das universidades tem, certamente, repercussões no processo de concepção e gestão de projetos", pois existem professores - mestres e doutores, disponíveis para os cursos, mas não tem política de liberação de carga horária para tal fim, que pode gerar "atividades esporádicas e que não 
contam com uma organização interna sólida, em que se priorize a articulação das funções de ensino, pesquisa e extensão, desvelam uma atitude pouco preocupada com o avanço do processo formativo do professor". Das instituições investigadas todas, com exceção de uma, organiza os cursos de extensão para formação de professores continuada, mediante parceria financeira, demonstrando o atendimento mercadológico e prestação de serviço, enquanto que uma "que não se organiza em função de incentivos existentes, mas objetiva avançar nos processo de investigação, de construção de novos conhecimentos, propostas metodológicas, tanto dos alunos da universidade que atuam no programa como dos docentes atingidos", demonstrando preocupação com a formação acadêmica. As instituições reclamam que não tem recursos humanos e condições estruturais suficientes para atenderem toda demanda, que parte da sociedade. Outra questão apresentada como dificuldade são as exigências do Estado em atender as demandas mas, sem apoio necessário. A possibilidade é que as "universidades podem constituir-se em redes de formação, elas poderiam se reunir para desenvolver esses projetos de capacitação de professores", enquanto isso "é possível notar uma ação clara de prestação de serviços, em que a universidade apenas aprimora as ações no intervalo entre uma demanda atendida e outra" e, que a avaliação desses cursos deve ser sistematizada, pois

“A dimensão avaliativa dos projetos ou está em embrionário processo de elaboração ou sequer foi incluída no momento da formulação dos cursos oferecidos. Por esse conjunto de dificuldades é urgente que as universidades realizem uma maior reflexão e análise dos caminhos políticos e metodológicos com que vêm formulando suas propostas para a formação continuada de professores."

O trabalho de Maia (2009) teve como objeto de investigação os trabalhos publicados pela Associação Nacional de Política e Administração da Educação (Anpae), por meio de duas revistas, sendo a Revista Brasileira de Política e Administração da Educação ( RBPAE) e nos Cadernos de Administração Escolar, de 1983 a 2000, sobre a formação dos profissionais da educação e o "possível papel da Universidade na formação e atuação dos administradores escolares, baseando-me em projeto desenvolvido entre uma Universidade pública e um sistema municipal de educação". A pesquisa não apresentou um problema em forma de pergunta. Os partícipes foram docentes e coordenadores pedagógicos de dez escolas. As discussões dispostas nos trabalhos convergiram para o pensamento dos defensores da Associação Nacional de Formação de Profissionais da Educação (Anfope), que "pretende a estruturação de uma política educacional global de formação e profissionalização do magistério para tratar da formação inicial; das condições de trabalho, do salário, da carreira e da formação continuada". Quanto ao projeto de ação que vinculava pesquisa, ensino e extensão, a secretaria municipal teve resistência e foi preciso buscar a parceria em outra cidade que aderiu a proposta com dez escolas da cidade. As atividades do projeto foram elaboradas 
coletivamente e de forma democrática, com avaliação ao longo de todo processo. Ficou evidente nos encontros que "O trabalho reflexivo das práticas profissionais desenvolvidas nas escolas, ao exprimir redes de significações partilhadas nas e pelas trajetórias de vida, coloca em evidência o caráter emancipatório dessas práticas". Para a autora "alguns aspectos presentes na construção do conhecimento sobre formação dos profissionais da educação nas publicações da Anpae, entre eles, merece destaque a insatisfação dos autores com o modelo educacional tecnoburocrático e centralizador" e defende uma formação de professores continuada com flexibilidade, autonomia por convivência e construções coletivas, que podem ocorrer com projetos que sejam "cada vez mais estreito entre Universidade e escolas públicas, projeto que reúne atividades de ensino, pesquisa e extensão ao propor a integração entre docentes de uma Universidade e profissionais de um sistema municipal de ensino", em que o diálogo, a problematização e participação coletiva e consciente sejam propulsoras das mudanças do fazer efetivo na formação de professores. O trabalho apontou que há críticas ao modelo educacional tecnoburocrático e centralizador e defesa de uma formação para autonomia e por construções coletivas, que podem ser realizadas nas instituições de ensino superior, por ações que visem a pesquisa, o ensino e a extensão.

Após a análise dos 11 trabalhos, apresentamos uma síntese de perspectivas e limites da formação de professores na extensão universitária, conforme Quadro 08.

\section{QUADRO 08. PERSPECTIVAS E LIMITES}

\begin{tabular}{|c|c|}
\hline Limites & Perspectivas \\
\hline $\begin{array}{l}\text { 1. falta políticas públicas e institucionais, } \\
\text { 2. falta engajamento da sociedade civil, } \\
\text { 3. faltam ações mais efetivas do Estado, } \\
\text { 4. insipiente atuação da instituição acadêmica, } \\
\text { 5. descontinuidade das ações, } \\
\text { 6. inexistência ou fragilidade de avaliação, } \\
\text { 7. fragilidade na formação inicial e atuação, } \\
\text { 8. marginalização quanto a pesquisa e ensino, } \\
\text { 9. tensionamentos na concepção de extensão, } \\
\text { 10. distanciamento entre a teoria e a prática, } \\
\text { 11. fragilidade curricular, } \\
\text { 12. fragilidade com a prática docente, } \\
\text { 13. cursos como prestação de serviço, } \\
\text { 14. atividades esporádicas, } \\
\text { 15. não há preocupação com a formação, } \\
\text { 16. visam o atendimento mercadológico, } \\
\text { 17. falta recursos humanos e condições estruturais. }\end{array}$ & $\begin{array}{l}\text { 1. existem ações permanentes, } \\
\text { 2. parte da realidade dos alunos, } \\
\text { 3. lócus de discussão e criação de metodologias, } \\
\text { 4. integra a universidade à comunidade, } \\
\text { 5. produz material didático e bibliográfico } \\
\text { 6. discute políticas públicas, } \\
\text { 7. visa avaliação contínua, } \\
\text { 8. fomenta a sensibilidade e coletividade, } \\
\text { 9. favorece a reflexão da trajetória formativa, } \\
\text { 10. tem a pesquisa tem campo fértil na extensão } \\
\text { 11. pode vir a ser redes de formação e colaboração, } \\
\text { 12. favorece a formação acadêmica e humana, } \\
\text { 13. potencializa a relação dialógica, } \\
\text { 14. favorece a interdisciplinaridade, } \\
\text { 15. possibilita a relação teoria e prática, } \\
\text { 16. possibilita uma práxis articuladora, } \\
\text { 17. imprime consistência teórica e operacional, } \\
\text { 18. fomenta a efetivação do tripé, } \\
\text { 19. fomenta a produção do conhecimento, } \\
\text { 20. possibilita a formação política, } \\
\text { 21. viabiliza o posicionamento na realidade, } \\
\text { 22. potencializa a sólida contextualização, } \\
\text { 23. potencializa uma revolução epistemológica, }\end{array}$ \\
\hline
\end{tabular}


24. potencializa uma episteme emancipatória,

25. viabiliza o conhecimento emancipador,

26. possibilita práticas emancipatórias.

Fonte: Produto da pesquisa.

São muitos os limites para uma formação de professores na extensão universitária, mediante os trabalhos analisados, mas as perspectivas dessa formação são também presentes. Destarte, emergiram as categorias de possibilidade de uma formação de professores tendo o espaço da extensão universitária como ambiência acadêmica, ou seja, como processo educativo: 1.a extensão é componente curricular, 2.promove a unidade teoria e prática, 3.fomenta a produção do conhecimento científico, 4.favorece a formação política e emancipadora, 5.a temporalidade das ações de extensão serem permanentes, 6.a assumência das instâncias competentes e 7.a efetivação do tripé universitário. A dialética e a contradição estão presentes nas categorias e que precisa ser analisado como tem sido concebida e praticada as ações extensionistas.

A categoria componente curricular aparece nos trabalhos, como sendo uma obrigatoriedade prevista por lei, como na LDB - Lei 9.394/96 -, visando o atendimento do tripé universitário, bem como no Plano Nacional de Educação como obrigatoriedade no currículo. Contudo, não basta ser regulamentado legalmente. É preciso condições de ser cumprido e com a devida qualidade no cumprimento da legislação.

A categoria unidade teoria e prática, precisa ser concebida enquanto práxis e de concepção crítica-emancipadora, visando a Meta 1 do PNEU e não meramente como um discurso de relação entre teoria e prática, mas de unidade teoria e prática.

A categoria produção do conhecimento científico, aparece como possibilidade nas ações extensionistas. Para isso é importante a concepção acadêmica e crítica, bem como uma continuidade das ações para o amadurecimento teórico-prático. Defendemos que a produção do conhecimento científico e acadêmico emerge, devido à organicidade e permanência das ações, bem como a relação dialógica que se efetiva, a consistência teórica e operacional que se alcança devido ao tempo dedicado às ações.

A categoria formação política e emancipadora, considera o pensamento crítico e político dos envolvidos nas ações extensionistas. A defesa é que para que isso ocorra seja importante ações permanentes e de concepção acadêmica, pois o assistencialismo e a prestação de serviços, podem não contribuir com as discussões para uma visão política, crítica e emancipadora.

A categoria temporalidade das ações de extensão, se expressa no tempo das atividades que podem ser esporádicas ou com continuidade do projeto. As ações de extensão enquanto processuais 
e permanentes, podem viabilizar um maior envolvimento dos acadêmicos sobre a sua trajetória de formação, fomentando o aprender e construir, coletivamente, no fazer do trabalho educativo, além de fomentar a sensibilidade e formação humana e acadêmica

A categoria assumência das instâncias competentes passa pela questão das instituições assumirem a extensão como promotora da formação acadêmica e reorganizar os currículos, fomentar bolsas de extensão, destinar carga horária aos docentes e financiamento das atividades extensionistas. A assumência também está na compreensão da concepção e do sentido das ações extensionistas, que podem vir a ser constituídas por congressos que tratam da temática com fomento a participação em eventos da área.

A categoria efetivação do tripé pesquisa, ensino e extensão é uma perspectiva presente em ações contínuas e processuais e também quando a instância acadêmica assume a extensão como parte integrante de suas atividades. Para isso é preciso a compreensão de que a universidade é o centro por excelência da pesquisa e esta viabiliza o ensino e a extensão ou a extensão viabiliza a pesquisa.

Com a análise dos dados do Estado do Conhecimento e pelas categorizações apresentadas é possível inferir que a extensão universitária apresenta-se como um espaço de diálogo fecundo e que precisa ser estabelecido nas instituições de ensino superior como prioridade de discussões e regulamentação.

\section{CONSIDERAÇÕES}

Considerando as possibilidades de formação de professores no espaço da extensão universitária, como componente curricular da universidade, pela concepção acadêmica processualorgânica é possível defender que possa vir a ser um espaço formativo que amplie a perspectiva para uma visão da educação como espaço da construção da crítica e emancipação. Compreendendo a extensão como ambiência acadêmica, pode-se ampliar a formação do professor para que ao imergir no processo da indissociabilidade pesquisa, ensino e extensão tenham novas possibilidades de compreensão do real e possam construir uma práxis que entenda a escola como o espaço formativo dentro de um contexto e no contexto da comunidade em que está inserida. 


\section{REFERÊNCIAS}

ABREU, Sandra C. Souza Reis. Universidade e escola básica: O papel da extensão universitária na formação de professoras e professores em educação científica. 2015. Disp.: <https://sucupira.capes.gov.br/sucupira/public/consultas/ coleta/trabalhoConclusao/viewTrabalhoConclusao.jsf?popup=true\&id trabalho=3216955 $>$.

CAMARGO, Maria Rosa R. Martins; MIGUEL, José Carlos; ZANATA, Eliana Marques. Travessias na Eja: a extensão universitária como ponte do fazer, do aprender, do pensar. 2015. Disp.: <http://www.scielo.br/pdf/ccedes/ v35n96/1678-7110-ccedes-35-96-00257.pdf> .

CASTRO, Aline T. Kroetz Ayres. Extensão Universitária e Formação Política na Universidade Pública: o caso Projeto Rondon na UFRGS e na UDESC. 2015. Disp.: <http://www.lume.ufrgs.br/handle/10183/134809>.

CUNHA, Ana Luiza Salgado A experiência como prática formativa de estudantes na extensão. 2013. Disp.: <http://locus.ufv.br/bitstream/handle/123456789/3443/texto\%20completo.pdf?sequence=1\&isAllowed=y>.

DUARTE, Jacildo da Silva. As contribuições da extensão universitária para o processo de aprendizagem, prática da cidadania e exercício profissional. 2014. Disp.: <https://bdtd.ucb.br:8443/jspui/handle/123456789/771>.

JUNIOR, Alcides Leao Santos A extensão universitária e os entrelaços de saberes. 2013. Disp.: < https://repositorio. ufba.br/ri/handle/ri/17554>.

MAIA, Graziela Zambão Abdian. Formação dos profissionais da educação: a Revista Brasileira de Política e Administração da Educação (RBPAE) e o compromisso da universidade. 2009. Disp.: <http://32reuniao.anped.org.br/ arquivos/trabalhos/GT08-5375--Int.pdf>.

OTALARA, Aline Piccoli. A formação de professores para o trabalho com deficientes visuais: uma experiência inicial de colaboração a partir do desenvolvimento de materiais didáticos. 2014. Disp.: <http://repositorio.unesp.br/ handle/11449/115667>.

RABELO, Francy Sousa. Educação não escolar e saberes docentes na formação do pedagogo: Análise de uma experiência no espaço hospitalar. 2014. Disp.: <http://www.uece.br/ppge/dmdocuments/dissertacao_francy_sousa rabelo.pdf>.

REIS, Renato Hilário. Histórico, tipologias e proposições sobre a extensão universitária no Brasil. Cadernos UnB Extensão: A universidade construindo saber e cidadania. Brasília, 1989. Disp.: < http://periodicos.unb.br/index.php/ linhascriticas/article/download/6094/5042>.

SANTOS, Sonia Regina Mendes. A universidade e a formaçào continuada de professores: Dialogando sobre a autonomia profissional. 2004. Disp.: <http://27reuniao.anped.org.br/gt08/t0820.pdf>.

ZIRGER, Juliana. Formação política na universidade: possibilidades a partir de (con)vivências na extensão/UFRGS. 2013. Disp.: <http://www.lume.ufrgs.br/handle/10183/772352013>. 


\section{RESUMO}

O artigo analisa os limites e as perspectivas quanto à formação de professores no espaço da extensão universitária como componente curricular da universidade, pelo estado do conhecimento revisitando periódicos A1, produções na Coordenação de Aperfeiçoamento de Pessoal de Nível Superior (Capes) e o GT 08 - Formação de Professores da Associação Nacional de Pós-Graduação e Pesquisa em Educação (Anped), pelo descritor "Extensão Universitária", no título, palavras-chave e resumo. A delimitação dos periódicos e produções foi de 2013 a 2016, enquanto que da Anped foi em sua extensão. Dos 1369 trabalhos encontrados, 11 discutiram formação de professores na extensão universitária, apontando que as ações de extensão visam ao assistencialismo e pouco contribuem na formação de professores.

Palavras-chave: Formação de Professores. Extensão Universitária. Perspectivas e Limites.

\section{TRAINING OF TEACHERS IN THE UNIVERSITY EXTENSION: AN ANALYSIS OF PERSPECTIVES AND LIMITS}

\section{ABSTRACT}

The analysis of the limits and the results of the university training of the curricular components of the university, the recognition and revision of the technical knowledge A1, productions of CAPES - The coordination of improvement of the higher levels of the personnel and The GT 08 - Training of Teachers of the National Association of Post-Graduation and Research in Education (Anped), by the descriptor "Extensão Universitaria", not title, keywords and abstract. A delimitation of newspapers and productions for the year 2013 to 2016, while the Anped was in its extension. Two 1369 papers found, 11 discussed teacher training in university extension, pointing out that as extension actions are aimed at assistencialismo and little contribute in teacher training.

Keywords: Teacher Training. University Extension. Perspectives and Limits.

\section{FORMACIÓN DE PROFESORES EN LA EXTENSIÓN UNIVERSITARIA: UN ANÁLISIS DE LAS PERSPECTIVAS Y LÍMITES}

\section{RESUMEN}

El análisis de los límites y los resultados de la formación universitaria de los componentes curriculares de la universidad, el reconocimiento y la revisión de los conocimientos técnicos A1, las producciones de la La reducción de perfeccionamiento de los niveles superiores del personal (Capes) y El GT 08 - Formación de Profesores de la Asociación Nacional de Post-Graduación y de Investigación en Educación (Anped), por el descriptor "Extensión Universitaria", en el título, palabras clave y resumen. La delimitación de los periódicos y las producciones para el año 2013 a 2016, mientras que la Anped fue en su extensión. De los 1369 trabajos encontrados, 11 discutieron formación de profesores en extensión universitaria, apuntando que como acciones de extensión apuntan al asistencialismo y poco contribuyen en formación de profesores.

Palabras-clave: Formación de Profesores. Extensión Universitaria. Perspectivas y límites. 